\title{
The English Reading Comprehension \\ Class: In-Reading and Post-Reading Strategies
}

\author{
Xinia Chacón
}

Universidad Nacional, Costa Rica

The main concern of teachers in a reading comprehension class is to make sure their students understand the texts. One way of reaching this goal is to provide learners with tools or strategies, teach them how to use them correctly, and encourage their use.

According to Oxford, a learning strategy is the technique, behavior, step, or action taken by the learner to develop a skill. They are useful because they help in the internalization, storage, retrieval and use of the new language. ${ }^{1}$ Shih believes that for these aids to work well the students have to learn how to set clear goals congruent with the task (criterion task) they want to develop. ${ }^{2}$ That is, if the goal of the students is to read for a test, they have to set different goals from those they propose for writing a paper, a summary, or drawing a semantic map. So the criterion task has to be established even before starting the reading process. Accordingly, pupils should differentiate the strategies to be used when the task is extensive reading (to grasp the main ideas) or intensive reading (to grasp the main ideas as well as the details). The information they have to obtain each time they read a text is different, and they should know how to approach it.

\footnotetext{
1. M. Shih, "Beyond Comprehension Exercises in the ESL Academic Reading Class," Tesol Quarterly, 26, 2 (1992) 289-311.

2. R. Oxford, "Language Learning Strategies in a Nutshell: Update and ESL Suggestions," Tesol Journal, 2, 2 (1992/1993) 18-22.
} 
Therefore, to understand a text readers have to discern how to handle not only pre-reading strategies, but also in-reading (duringreading) and post-reading strategies. Pre-reading strategies prepare the student for what comes in the text. Some of these strategies are: grammar and vocabulary work, development of background knowledge, oral questions, observation of text layout (title, headings, subheadings, pictures, charts, tables, words in boldface or italics, numbers, columns, etc.), guessing, brainstorming, semantic mapping, skimming, and scanning. Pre-reading strategies are not the goal of this paper since they were included in a previous number of this journal; ${ }^{3}$ nevertheless, in-reading and post-reading strategies are. These strategies will be discussed here with the idea that classroom reading mostly requires intensive reading. This paper is thought of as a guide for educators, so the strategies will be presented and guided in the reading class by the teacher hoping that these tools can be emulated by the students later in the classroom or in other settings.

In-reading strategies are those the reader applies while $\mathrm{s} / \mathrm{he}$ is in the process of decoding the reading, and post-reading strategies are those applied after the reading of the text has been completed. This paper proposes the following in-reading strategies: guessing, silent reading, self-questioning, vocabulary attack skills, dictionary use, fact/opinion, text organization, underlining, note-taking, paraphrasing, graphic organizers, comprehension questions, cloze exercises, and inference. It also presents the following post-reading strategies: vocabulary and grammar review, graphic organizers, summary, critical reading and problem solving (agree/disagree, relate to own experience, compare/contrast, discuss, apply), main idea, comprehension questions, inference, scanning, and skimming.

3. X. Chacón, “Students' First Approach to Reading Comprehension: Pre-Reading Strategies," Letras, 32 (2000) 121-136. 


\section{IN-READING STRATEGIES}

One in-reading strategy is guessing. An activity to develop this strategy is to have learners read the text in 'chunks' (an introduction, a paragraph, etc.) and stop after each one to talk about the main ideas and guess what comes next. This activity can be done in small groups or as a class. Stoller alleges that learners soon realize the different interpretations people give to the contexts. It is good to discuss these differences, and link them to the way people understand and analyze things depending on their previous experience. ${ }^{4}$

Very linked to guessing is the strategy of self-questioning. In an article written by Shih, Jakobowitz affirms that skilled readers need to ask themselves mental questions not only at the pre-reading stage, but also at the in-reading and post-reading stages. In the same article, Davey and Irvin claim that readers should ask themselves questions such as: What did I just read? Did I understand what I just read? What will come next? They assert that these questions are useful to monitor comprehension. ${ }^{5}$ In addition to that, Stoller proposes asking learners to underline or highlight the answers to the questions they previously asked to themselves. ${ }^{6}$

It is also important to ask students to do sustained silent reading. Morris and Zinn mention studies carried out by some authors on this respect. According to Coley and Farrell, two of these authors, silent reading improves comprehension, vocabulary scores, and increases at-home reading. Hayes, on the other hand, states that silent reading increases the schemata (the knowledge readers have in long-term memory) of poor adult readers which in turn permits them to infer more information from the text. ${ }^{7}$

4. $\quad$ F. L. Stoller, "Making the Most of a News Magazine Passage for Reading-Skills Development," English Teaching Forum, 32, 1 (1994) 2-7.

5. M. Shih, 289-311.

6. F. Stoller, 2-7.

7. L. A. Morris \& A. Zinn, "Areas in Practice: A Workshop Format for Developmental Reading Classes," Journal of Developmental Education, 18, 3 (1995): 26-27. 
Shih considers that it is important for students to be aware of certain textual signals and have text organization knowledge to better understand a text. ${ }^{8}$ This will let them establish certain relationships among the ideas in the reading. For instance, if a student is aware of the different types of patterns of organization writers use to organize the information such as: cause/effect, time order, definition, classification, listing, process, analogy, comparison/contrast, and description, s/he can analyze how the information has been put together and understand the passage s/he is reading a lot better. The same author adds some ideas of Van Dijk who proposes a list of signals a reader should pay attention to: letter size, italics, underlining; introductory and closing words (e.g. 'consequently,' 'in other words,' 'on the other hand,' 'likewise,' 'due to,' 'first'), repetition of certain words and phrases (similar to, opposed to, like, group, type, different from, months, years, steps, stages, etc.), and structure of the text (narrative, story, expository). ${ }^{9}$

Another in-reading comprehension strategy is the use of graphic organizers. While reading ask learners to scribble down a graphic organizer (draw a semantic map, fill in a chart or table on similarities and/or differences, put steps of a process in order, arrange periods in chronological order, etc.) that will help them put the ideas together, establish relationships among facts, and understand the content. They can use the pattern of organization (cause/effect, process, classification, etc.) of the text to do it.

Strategies to develop vocabulary attack skills are essential. Clarke and Silberstein oppose giving lists of vocabulary with definitions out of context because words are vehicles of meaning and seldom appear in isolation. Within a holistic approach, vocabulary strategies are taught in the context of the texts being read and studied. ${ }^{10}$ Students

\footnotetext{
8. M. Shih, 289-311.

9. M. Shih, 289-311.

10. M. A. Clarke \& S. Silberstein, "Toward a Realization of Psycholinguistics Principles in the ESL Reading Class," Language Learning, 27, 1 (1977) 135-154.
} 
must be taught how to identify key words basic for the comprehension of the text such as those in the title, headings, topic sentences, or words that recur. Once they do this, students should be aware of the different possibilities for guessing the meanings of words in context; for instance, the students continue reading and try to infer or obtain a general idea of the unfamiliar word. In addition, the teacher can point out the ways in which writers use redundancy of language to give readers some clues on meaning such as: synonyms, antonyms, definitions, explanations, cause and effect, association between an object and its function, descriptions, examples, comparison/contrast and cause/effect relationships, etc. Instructors can also teach how to guess the meanings by using morphology, or how to sketch semantic networks between the new words and concepts, and those the students already know. Without overwhelming the students with deep explanations the teachercan explain syntactic, discourse, and punctuation clues to explain contexts in which unfamiliar vocabulary appears.

For the use of the dictionary students should prioritize the unfamiliar vocabulary they encounter in texts. Some words can be inferred from the context using semantic and syntactic clues. Other words can be ignored. It is important to tell the students that they do not necessarily need to know every single unknown word. But still others should be looked up in the dictionary or in a glossary for specialized vocabulary. Nevertheless, there should be a balance; students must not become completely dependent on the dictionary or completely detached from it. Students should use the dictionary as a last resort, and only if context and morphological analysis fail because the excessive use of a dictionary affects the reading process making it slow, tiresome, and boring.

Furthermore, they should be taught how to use the dictionary. The teacher should not take for granted that the students know how to use a bilingual or an English monolingual dictionary. It is important to teach them how to discriminate among the different meanings the dictionary provides because they tend to pick the first meaning that 
appears in the entry and automatically discard the rest. It is useful to point out how the dictionary furnishes clues in parentheses to help the user find the adequate meaning according to the context of the word. Students also need to be taught other salient aspects on dictionary use: how to find the words in accordance with their function, and how to find the idiomatic expressions, and verbal phrases.

Another significant aspect is to let students know that depending on the reading purpose they may have, they need to look up for fewer or more words in the dictionary. If the learners are interested in reading to grasp main ideas to decide if a close reading of the text is necessary, they do not need to look up for the meanings of many unknown words. If the purpose is reading to write a research paper, or to take a test; for instance, the students have to search for the meanings of more words.

For an additional in-reading strategy, Wiesendanger and Bader advise instructors to teach learners how to differentiate facts from opinions, and be able to draw them from the text. This type of strategy helps students discriminate what information is relevant and what is not, go from the literal to the interpretative and back to the literal information, notice similarities and differences, and learn how to select key words. There are words or phrases that can give hints on opinions: 'I think,' 'I believe,' 'it is thought that,' 'apparently,' 'from my point of view,' 'it is my opinion that,' 'I can infer,' etc. Others introduce facts that are usually supported by some kind of data, a general truth or common true knowledge: 'In fact,' 'it has been proven,' etc. ${ }^{11}$

A different strategy is underlining, note-taking andparaphrasing . Shih mentions ideas of McAndrew which suggest that good strategies are better applied if the student owns the material and is willing to underline and annotate in the margins. Instructors should teach the

11. C. Wiesendanger \& L. Bader, "SCAIT: a Study Technique to Develop Students' Higher Comprehension Skills when Reading Content Area Material," Journal of Reading, 35, 5 (1992) 399-400. 
students how to use these markings to enhance comprehension; otherwise, an incorrect application of them may hinder it. Underlining and note-taking serve two functions: as external storage mechanisms (helping the student to keep information for later study or use) and as encoding mechanisms during the reading process (helping the student to focus on the most important ideas or points). When students can discriminate main from secondary sentences, and they mark (underline or take notes) the main or the higher level superordinate sentences that require a deeper mental processing, they recall the ideas better and understand the text better. ${ }^{12}$

In order to underline or take notes students have to read section by section, first reading and then rereading and underlining so that they have a clearer and wider understanding of the content and know what ought to be underlined. Underlining and note-taking have to be in accordance with the task. If the learners are reading for personal interest they have to be able to set up their own goals. In other words, if they are reading a text on tropical forests and they are interested in tropical birds, they should focus and underline or take notes on this specific information. If the students are in class or are reading for an assignment and they do not understand what the objective of the reading activity is, they must ask for clarification from the instructor. The students have to be clear about the purpose of the markings.

Shih believes that underlining has a disadvantage because it does not separate main ideas from examples, or provide the opportunity to comment on or react to the material, whereas taking notes in the margin provides more valuable and meaningful information. ${ }^{13} \mathrm{Good}$ annotations can make underlining unnecessary. Underlining and annotations are helpful tools for the students to monitor comprehension, but paraphrasing, which is another way of taking notes, makes the reader process the text at a deeper level. Paraphrasing means to write

12. M. Shih, 289-311.

13. M. Shih, 289-311. 
the author's ideas in the students' own words without changing the original meaning. The teacher should teach how to paraphrase and provide the students with a lot of practice.

There are some suggested strategies for annotations. Students can write main ideas, paraphrased ideas, reflections, personal comments, quotations, words or phrases on note cards orconceptcards that they can use later to summarize facts, or to make informal outlines that will show relationships between ideas. Santa, Havens, and Harrison, mentioned in Shih, suggest two-column notes, the left column for key ideas, and the right column for elaboration or comments. ${ }^{14} \mathrm{~A}$ similar possibility is to write summary notes, topics, subtopics, key ideas, or functions of specific portions of the reading in the left margin of the text, and commentaries, and reactions in the right margin in order to form the text's macrostructure later. In addition, Smith and Tompkins, also in Shih, propose structured note-taking, a combination of an informal outline and a graphic representation. ${ }^{15}$ Stoller, on the other hand, recommends that instructors give learners a "skeletal framework" as a guideline that students can fill out while reading. ${ }^{16}$ Students can also take notes on a separate sheet of paper to facilitate checking their main ideas with the ones the teacher or other classmates may be writing on the blackboard, or sharing orally in class later as a postreading activity.

Khan proposes certain features for note-taking: brevity (brief and to the main point), relevance (the ideas that fit the purpose), clarity (no ambiguity), note form (outline, table, etc.), and abbreviations and symbols. For the last one, the reader can use: capital letters (U.N., United Nations), the first letters of a word ( $a b b r$, abbreviation, $a d j$, adjective ), the first and last letters of a word (gov't, government; int 'l, international, $p t s$, points). There are also some other standard symbols such as: e.g. (for example), viz (namely), \& (and), i.e. (this is), and \%

\footnotetext{
$14 . \quad$ M. Shih, 289-311.

15. M. Shih, 289-311.

10. F. Stoller, 2-7.
} 
(percentage). The author also suggests that students create their own symbols, but they have to be able to decipher them at a later time. ${ }^{17}$

According to Shih, when taking notes for test purposes, the student should target definitions, examples, names, dates, events, lists, cause/effect, and comparison/contrast patterns. ${ }^{18}$ When the information the students need is specific, Stoller suggests that teachers prepare question grids or tables for the learners to fill out. ${ }^{19}$

Inference is another skill that has to be developed in a reading class. Sometimes it is hard for the students to understand implicit information. The teacher can develop this skill by preparing comprehension questions that require to infer information and be marked easily while reading the text, such as true and false, matching, multiple-choice, and cloze exercises. A cloze exercise is a text in which there are some missing words that the reader has to fill in inferring the information from the rest of the text. These exercises will teach them how to infer words and phrases by context, and enrich the content by reading beyond the lines. The teacher can prepare a few of these types of questions per paragraph so that they can be answered as the student is decoding the message or understanding the content of the text.

\section{POST-READING STRATEGIES}

Post-reading strategies are those strategies the reader applies after he has read the text and has a complete picture of it. The tcacher can use these strategies for reinforcement, evaluation, and application. When reinforcing, the teacher can review vocabulary, grammar or reading comprehension strategies. When evaluating, the educator can verify if the students understood the content, or used the reading strategies, vocabulary and grammar correctly. S/he can do it through comprehension questions or other activities that may include round

\footnotetext{
17. A. Khan, "Note-Taking," English Teaching Forum, 37, 2 (1999) 18-19.

18. M. Shih, 289-311.

19 F. Stoller, 2-7.
} 
tables, debates, group work, discussion, etc. If the teacher notices that any aspect (content or strategy) was not mastered to the level s/he wanted to, s/he can go back and explain it again or provide more practice. When applying the content of the reading just read to new situations, the teacher can prepare solving-problem or critical reading activities.

To evaluate reading comprehension, it is of primary importance to pay attention to some suggestions expressed by authors on the design of comprehension questions. According to Kissok and Iyortsuum (in Salwa) the type of questions the teacher asks, the information the learners draw, and the mental processes these questions activate determine the level of comprehension the instructor is looking for. ${ }^{20}$ In this case, Bloom's taxonomy is helpful in determining what level of cognitive domain the teacher wants to elicit. As mentioned by Abdul Ghani, this taxonomy includes knowledge, comprehension, application, analysis, synthesis, and evaluation (see table 1). ${ }^{21}$ The teacher should first choose the type of domain s/he wants to evaluate and then design the questions accordingly.

For Clarke and Silberstein if the instructor is going to ask for thorough comprehension, s/he should prepare comprehension questions that ask for accessible information. One way for the teacher to do this is by reading the text and writing comprehension questions about the main points s/he remembers. The students may not remember more than s/he does. ${ }^{22}$

Moreover, teachers should be careful to write comprehension questions that develop such reading skills as finding main ideas, details, or arguments; guessing unknown words by using the context clues; and increasing linguistic competence (e.g. grammar and morphology). Along the same lines, Stoller asserts that teachers

20. G. Salwa, "ESP Reading: Some Implications for the Design of Materials," English Teaching Forum, 31, 4 (1993) 42-44.

21. S. Abdul Ghani, "ESP Reading: Some Implications for the Design of Materials," English Teaching Forum, 31, 4 (1993) 42-44.

22. M. A. Clarke, \& S. Silberstein, 135-154. 


\section{Table 1 \\ Cognitive levels of comprehension}

Question

Name the hormone

that regulates

sugar in the blood

Define "element."

(what is an element?)

List the uses of sulfur Listing

Definition

Comparison

properties of metals

and nonmetals

Describe how you

would separate

powdered copper

sulphate and powdered

copper (Hart 1984)

Classify rocks and describe each type

Classification and physical

description

Process

\section{Thought process Cognitive level}

Recall

Knowledge

Recall

Knowledge

Recall Knowledge

Understanding

Comprehension

Understanding Comprehension

Understanding Comprehension

Suggest uses for the

Combination of

Understanding

Application

alkanes (Hart 1984)

and using

information 


\begin{tabular}{|lll}
\hline $\begin{array}{l}\text { Explain why a bottle of } \\
\text { concentrated }\end{array}$ & $\begin{array}{l}\text { Explanation } \\
\text { (cause and effect) }\end{array}$ & $\begin{array}{l}\text { Understanding } \\
\text { and using } \\
\text { information }\end{array}$ \\
$\begin{array}{l}\text { fumes when it is opened } \\
\text { in a warm room, yet a }\end{array}$ & \\
$\begin{array}{l}\text { bottle of dilute hydrochloric } \\
\text { acid does not (Hart 1984) }\end{array}$ & \\
\hline
\end{tabular}

\begin{tabular}{llll}
$\begin{array}{l}\text { How can the problem } \\
\text { of dust pollution be } \\
\text { solved? }\end{array}$ & $\begin{array}{l}\text { Combination } \\
\text { of language functions }\end{array}$ & Creating ideas & Synthesis \\
\hline & &
\end{tabular}

$\begin{array}{llll}\begin{array}{l}\text { What do you think of } \\ \text { mercy killing? Which }\end{array} & \begin{array}{l}\text { Combination } \\ \text { of functions }\end{array} & \begin{array}{l}\text { Creating } \\ \text { ideas } \\ \text { is better: nuclear }\end{array} & \text { Evaluation } \\ \text { energy or solar } & & \\ \text { energy? Discuss } & & \end{array}$

Source: S. Abdul Ghani, "ESP Reading: Some Implications for the Design of Materials," English Teaching Forum, 31, 4 (1993) p. 43.

should prepare questions that inspire learners to use scanning and skimming to find the answers. In addition, teachers should ask learners to answer open-questions that allow for different interpretations and points of view. Another possibility is to ask questions in which the learners have to infer certain information from the text; for example, the author's attitude and purpose. Students should not be afraid to read beyond the lines, but at the same time they must know that inferences are educated guesses. A different option is to prepare a list of events from the reading and ask the learners to sequence them in chronological order. Also, teachers should ask learners to check the previous assumptions they made during the pre-reading and during-reading activities, as suggested by Hind and Brancard (in Stoller). ${ }^{23}$

2.3. F. Stoller, 2-7. 
But most important of all is to take into account criterion tasks when writing questions. Anderson and Armbruster (in Shih) believe it is more important to focus on criterion task demands. A criterion task, as mentioned earlier, is a real task students want or need to do, so the act of reading a text is the answer or the solution for the task. ${ }^{24}$ If they read the text for a specific task (to look for specific information, to prepare a presentation, to study for an exam, etc.), the teacher should be aware of this and be ready to prepare questions that fit the task goals.

For vocabulary and structure review Dubin alleges that in postreading exercises teachers should reintroduce words already studied in pre-reading and during-reading activities. This inspires learners to reinforce the vocabulary they already encountered in the text. ${ }^{25}$ In particular, Dubin and Olshtain suggest that teachers ask the students questions like the following: The text you just read had the word 'device' in several phrases and expressions, how many can you find? Another question could be: How do these words relate to the rest of the reading content? ${ }^{26}$ If the teacher emphasized a particular structure or lexis as a pre-reading strategy, post-reading activities are a good opportunity to review it in context. Cloze exercises work well to review structure and vocabulary (Milne). ${ }^{27}$

If students wrote semantic maps as a pre-reading strategy, they can check again the semantic maps as a post-reading activity to verify if they were accurate. They can also expand them or make new ones. According to Heimlich and Pittelman (in Stoller) semantic maps or graphic organizers of any type, help learners work in groups to find a solution, comprehend, assess and organize the information in the reading at a conscious level. ${ }^{28}$

\footnotetext{
24. M. Shih, 289-311.

25. F. Dubin, "Learning New Vocabulary Through Context: Insights from Materials Preparation," Journal of Intensive English Studies, 3, Spring/Fall (1989) 37-49.

26. F. Dubin \& E. Olshtain, Course Design (New York: Cambridge University Press, 1994).

27. D. Milne, "Reading-Comprehension Material for Science Students," English Teaching Forum, (1989) 37-38.

28. F. Stoller, $2-7$.
} 
It is essential to teach learners how to make their own conceptual maps, graphic organizers, semantic maps, cognitive maps, semantic organizers, networks, tables, graphs, etc. (as different authors call them) to organize the main ideas and the supporting details. Conceptual and semantic maps, two of the most commonly used maps, are helpful because they show a visual representation of the relationship of words and phrases. The difference between the two of them is that in a conceptual map the phrases or words are joined by linking words (e.g. prepositions), and in a semantic map these words are not used. Both are graphical representations that take the shape of rectangles, squares or circles linked by arrows that arrange ideas in the form of key words or phrases. Both maps can be used better with certain contents than with others, or by students whose style of learning is more graphic. Carrell, Pharis, and Liberto, in Shih, found that ESL students trained in conceptual maps did better in open-ended, short-answer questions than those who did not receive the training. It is also known that conceptual maps are helpful for recall. ${ }^{29}$

The instructor should encourage students to write a summary. Shih agrees with Anderson and Armbruster who mention that when students write summaries they rework in a deeper way the information included in the notes and match that information with the reading tasks they had proposed. The same authors believe that it is basic for students to write summaries to organize or rehearse the information of the text. ${ }^{30}$ The instructor should guide students to write summaries. S/ he should ask students to write careful notes from the information that is underlined, and from the notes written in the margin of the text or on separate sheets of paper. This information which is written in the form of comments, paraphrasing, and exact quotations is then put together in a cohesive, coherent way.

29. M. Shih, 289-311.

30. M. Shih, 289-311. 
This is also a good time to ask learners to extract the main idea of the text. During the in-reading process they searched for the main ideas of each paragraph, as a post-reading strategy they can discuss what the main idea of the whole text is.

It is also important to do critical reading and problem-solving activities which are a way to give sense to the material read by applying it to the students' own experiences analyzing, evaluating, and reflecting on the content. This strategy will allow students to learn something. For critical reading, De Vasconcelos and Santiago suggest asking learners to compare the knowledge just learned in the reading with their previous experience and induce them to express their own points of view. ${ }^{31}$ It is a good idea for the instructor to look for texts that present contrasting points of view or that provoke certain reactions from the reader, and set aside some class time for discussion. Also, the students may be asked to look for other articles related to the same topic studied in class, and then be asked to review, synthesize, summarize, compare or contrast, and give their points of view (agree/disagree). One more option, proposed by Stoller, is to ask learners to apply the information from the readings to activities that are interesting to them and that will allow them to go beyond the text. ${ }^{32}$ These activities could be to write an assignment, prepare an oral presentation, or do any kind of problem-solving activity.

Even though the names of some strategies repeat under inreading and post-reading strategy headings, their focus is different. During the application of in-reading strategies, the student is in the process of decoding the content of the text. During the application of postreading strategies the student already has the whole picture of the text.

To conclude, it should be paramount that students know how to use reading strategies-how to combine and choose the appropriate

31. J. De Vasconcelos \& V. Santiago, "Designing ESP Materials for University Students," English Teaching Forum, 30, 4 (1992) 36-37.

32. F. Stoller, 2-7. 
strategies to accomplish a task. In this way, they can become more independent learners.

The teacher, on the other hand, will interweave strategies with class work tasks, and not teach them as a unit separate from the development of the reading skill. S/he should study what strategies the students lack, which they have, which work better for each task, and how their learning styles can affect their learning strategies through informal talking in the classroom, surveys, and observation. With the help of teachers and strategies, learners will understand the reading comprehension process better. 